\title{
Brachytherapy dose received by bladder and rectum in patients with inoperable cervical cancer: CT-based 3D view
}

\author{
Goran Marošević ${ }^{1}$, Hasan Osmić ${ }^{2}$, Semir Fazlićn ${ }^{2}$ Dušan Mileusnić ${ }^{3}$, Jovan Babić ${ }^{1}$
}

${ }^{1}$ Center for radiotherapy, International Medical Centers, Banja Luka, Bosnia and Herzegovina ${ }^{2}$ Department for Radiotherapy, University Clinical Center Tuzla, Tuzla, Bosnia and Herzegovina ${ }^{3}$ Department for Radiotherapy, Military Medical Academy, Belgrade, Serbia

As recommended by the GEC-ESTRO work group, it is important for the 3D image guided CT, or MRI based brachytherapy of cer-

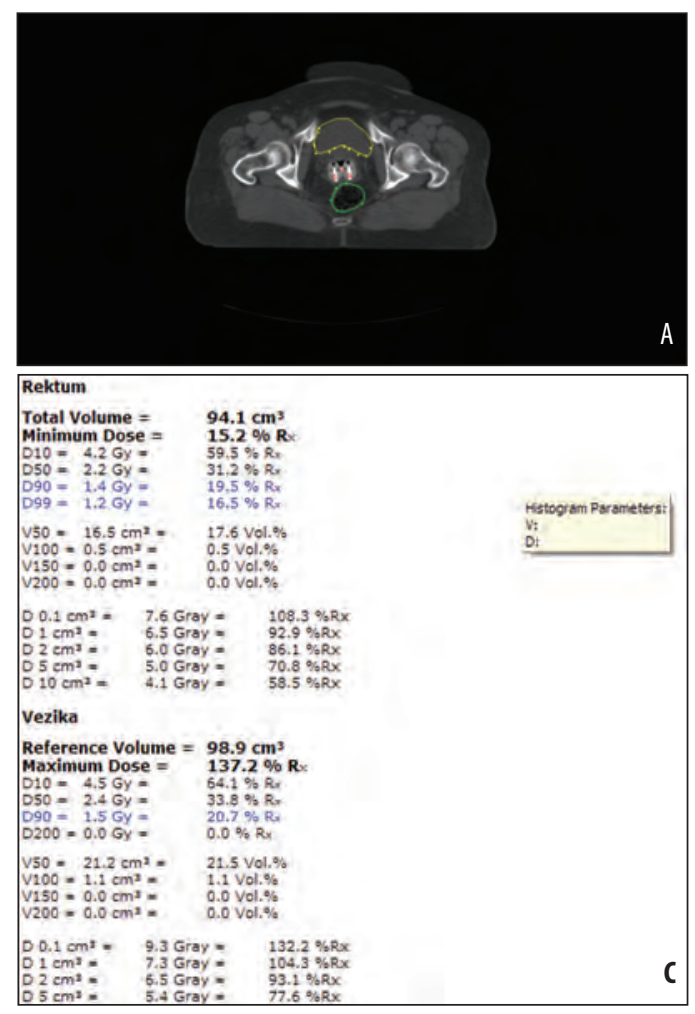

vical cancer to verify what dose is received by $0.1 \mathrm{~cm}^{3}, 1 \mathrm{~cm}^{3}$ and $2 \mathrm{~cm}^{3}\left(\mathrm{D}_{0,1 \mathrm{ccc}}, \mathrm{D}_{1 \mathrm{cc}}\right.$ and $\mathrm{D}_{2 c \mathrm{c}}$, respectively) of the bladder and rectum volume (1). Intracavitary brachytherapy was applied with applicators type Fletcher tandem and ovoids, once a week on a HDR regime (high dose rate). Delineation of organs at risk (bladder and rectum) was made after each computer tomography (Panel A). The bladder and rectum were delineated on each
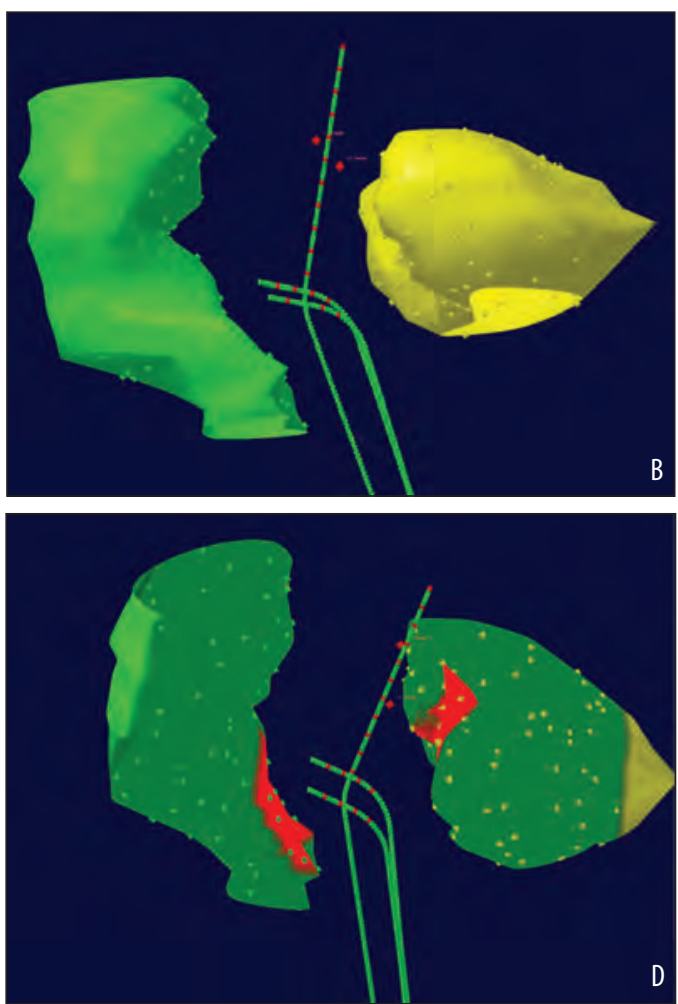
CT slice: the rectum was delineated at $1 \mathrm{~cm}$ from the anus to the recto-sigmoid transition through the entire thickness of the organ wall, and the bladder was delineated following the outer contour of the entire organ volume (Panel B). The therapy dose of $(5 \mathrm{x}$ 7 Gy) was prescribed according to the Manchester system, to the A point. Brachytherapy $\mathrm{D}_{0,1 \mathrm{ccc}}, \mathrm{D}_{1 \mathrm{cc}}$ and $\mathrm{D}_{2 \mathrm{cc}}$ doses for the bladder and rectum were established for each application (Panel C). The $\mathrm{EQD}_{2}$ (total biologically equivalent dose in $2 \mathrm{~Gy}$ ) for bladder and rectum were $76.7 \mathrm{~Gy}$ and $81 \mathrm{~Gy}$, respectively. Also, we could see the position (three - dimensional view) of the brachytherapy dose received by bladder and rectum (Panel D). In planning brachytherapy, CT does not give us the possibility to precisely delineate the tumor and plan the distribution of the therapy dose to the tumor (as is the case with MR planning). However, it is possible to obtain precise data on the contribution of the brachytherapy dose to the organs at risk (2).

Key words: D2cc, Brachytherapy, Cervical cancer.

Authors' contributions: Conception and design: GM; Acquisition, analysis and interpretation of data: GM and SF; Drafting the article: GM and HO; Revising it critically for important intellectual content: JB and DM.
Conflict of interest: The authors declare that they have no conflict of interest.

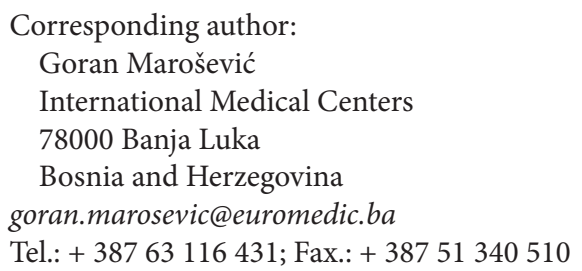

Copyright (C) 2013 by Academy of Sciences and Arts of Bosnia and Herzegovina. E-mail for permission to publish:amabih@anubih.ba

\section{References}

1. Pötter R, Haie-Meder C, Van Limbergen E, Barillot I, De Brabandere M, Dimopoulos J, et al. Working Group. Recommendations from gynaecological (GYN) GEC ESTRO working group (II): concepts and terms in 3D image-based treatment planning in cervix cancer brachytherapy-3D dose volume parameters and aspects of $3 \mathrm{D}$ imagebased anatomy, radiation physics, radiobiology. Radiother Oncol. 2006;78(1):67-77.

2. Viswanathan AN, Dimopoulos J, Kirisits C, Berger D, Potter R. Computed tomography versus magnetic resonance imaging-based contouring in cervical cancer brachytherapy: results of a prospective trial and preliminary guidelines for standardized contours. Int J Radiat Oncol Biolo Phys. 2007;69:963-4. 